\title{
PULSE-RATE AND BLOOD-PRESSURE IN INFANCY AND EARLY CHILDHOOD
}

\author{
BY
}

\author{
G. M. ALLEN-WILLIAMS, M.D., D.P.H. \\ From the Institute of Social Medicine, Oxford
}

There have been few carefully recorded and analysed studies of the resting pulse in healthy children, and knowledge of pulse variation in the early years of life is mainly based on observations made on sick or convalescent subjects. The same is true of blood-pressure readings.

An investigation of anthropometric methods, preparatory to a socio-medical study of growth and development in the pre-school child and carried out in the municipal day nurseries in Oxford, offered an opportunity for studying the resting pulse-rate and the ranges of blood-pressure in healthy children at ages six months to five years under standard conditions.

\section{Pulse-rates}

The observations on the pulse were made between January and March in six of the day nurseries, where a state registered nurse was in charge. The pulse-rates were taken daily for a week, half-way through the afternoon rest hour, when the children had been soundly asleep for some time. The readings of the children who woke, who were unsettled, or who became excited with this departure from routine, were not included in the records. The results are shown in table 1 , which gives the average value of the pulse-rates in children according to age and sex.

TABLE 1

\begin{tabular}{|c|c|c|c|c|c|c|}
\hline & \multicolumn{3}{|c|}{ Males } & \multicolumn{3}{|c|}{ Females } \\
\hline $\begin{array}{c}\text { Age } \\
\text { yr. }\end{array}$ & Total & $\begin{array}{c}\text { Mean rate } \\
\pm \text { S.E. }\end{array}$ & C.V. & Total & $\begin{array}{c}\text { Mean rate } \\
\quad \pm \text { S.E. }\end{array}$ & C.V. \\
\hline $\begin{array}{l}\frac{1}{2}-1 \\
1-2 \\
2-3 \\
3-4 \\
4-5\end{array}$ & $\begin{array}{r}5 \\
21 \\
18 \\
29 \\
17\end{array}$ & $\begin{array}{l}122 \cdot 0 \pm 4 \cdot 21 \\
102 \cdot 2 \pm 2 \cdot 26 \\
100 \cdot 4 \pm 1 \cdot 23 \\
100 \cdot 0 \pm 1 \cdot 49 \\
100 \cdot 8 \pm 1 \cdot 41\end{array}$ & $\begin{array}{r}7 \cdot 7 \\
10 \cdot 0 \\
5 \cdot 2 \\
8.0 \\
5.8\end{array}$ & $\begin{array}{r}6 \\
20 \\
14 \\
26 \\
25\end{array}$ & $\begin{array}{l}109 \cdot 3 \pm 3 \cdot 72 \\
110 \cdot 0 \pm 2 \cdot 30 \\
106 \cdot 0 \pm 1 \cdot 95 \\
102 \cdot 0 \pm 2 \cdot 26 \\
100 \cdot 7 \pm 1 \cdot 15\end{array}$ & $\begin{array}{r}8.4 \\
9.8 \\
6.9 \\
11.3 \\
5.7\end{array}$ \\
\hline
\end{tabular}

S.E. $=$ Standard Error. C.V. $=$ Coefficient of Variation.

The mean pulse-rate in children aged six to twelve months is 122 beats per minute for males and 109 for females, but it should be noted that these rates are based on a small number of children.
At one to two years the values for males and females are 109 and 110 respectively. At two to three years the pulse-rate falls to 100 among males and remains at this level up to five years. This sudden decrease is significant, and not due to chance fluctuation. The pulse-rate among females declines regularly from one year old. There is a decrease of 3 beats per minute for each increase of one year in age. At four to five years the mean pulse-rate in both sexes is identical.

The significance of the differences in pulse-rates according to age and sex were measured statistically by the ' $t$ ' test. The observed differences proved unimportant, with one exception. In the two to three age-group the pulse-rate of 106 per minute among females was significantly higher than the rate of 100.4 per minute found in the males.

Halverson (1941) found that in healthy full-term infants the pulse-rate varied from 108 to 160 per minute in the new born; from 95 to 156 in the first month; and averaged 120 per minute during the first year, with a diurnal variation of 30 to 50 beats per minute, according to external factors affecting the pulse-rate. During sleep the mean rate was 123.5 per minute. These figures represent the average findings on 18 male and 25 female infants. There was no difference between the sexes. Schlesinger (1932) studied the sleeping pulse-rate in 131 rheumatic and 100 'healthy' convalescent children, age three months to fifteen years. He found that in the ' healthy' control individuals under one year ( 11 children) the sleeping pulse-rate was 113 to 119 per minute; and from one to two years (7 children) the rate was 99 per minute; and from two to five years ( 17 children) it averaged 84 per minute.

These rates are lower than those in the present series and those found by Halverson, possibly due to the fact that these records were made on convalescent children who were not in complete health, and who may therefore not have regained their normal vasomoter tone. There is appreciable variability around the average pulse-rate in any group of children, and rates recorded on the same child under varying conditions may show differences of 10 to 40 per minute. (Benedict and Talbot, 1914; Sutherland and McMichael, 1928.) In the present series the environmental factors which may 
influence the pulse-rate were held constant, and only the sleeping pulse was considered. The variation around the mean rate which occurred in the different age-groups is shown in table 1 by the coefficient of variation. The greatest dispersions were of the order of 11 per cent. in the females of three to four years, and 10 per cent. in the males of one to two years. These pulse-rates were recorded on six successive days for each child. To find whether the variation in the consecutive readings of the pulserate in the individual was of greater or less importance than the variation between the children, an analysis was made of the records in the three to four age-group, which formed the largest section of the population under review. The results shown in table 2 clearly indicate that the variation between children is much the more important factor, since the criterion-the value of $\mathrm{Z}$-is less than the $0 \cdot 1$ per cent. level in both males and females.

TABLE 2

\begin{tabular}{|c|c|c|c|c|}
\hline $\begin{array}{l}\text { Source of } \\
\text { variation }\end{array}$ & Degrees & $\begin{array}{c}\text { Sums of } \\
\text { squares }\end{array}$ & Quotient & \\
\hline \multicolumn{5}{|c|}{ Males 3-4 years } \\
\hline $\begin{array}{l}\text { Between } \\
\text { children.. } \\
\text { Between days } \\
\text { Residual .. } \\
\text { Total } \quad . .\end{array}$ & $\begin{array}{r}24 \\
5 \\
120 \\
149\end{array}$ & $\begin{array}{r}9716 \cdot 34 \\
136 \cdot 16 \\
5307 \cdot 50 \\
15160 \cdot 00\end{array}$ & $\begin{array}{r}404 \cdot 85 \\
27 \cdot 32 \\
44 \cdot 22 \\
\\
101 \cdot 75\end{array}$ & $\begin{array}{l}\mathrm{Z}=1 \cdot 11 \\
0 \cdot 1 \text { per cent. } \\
\quad=0.29\end{array}$ \\
\hline \multicolumn{5}{|c|}{ Females 3-4 years } \\
\hline $\begin{array}{l}\text { Between } \\
\quad \text { children.. } \\
\text { Between days } \\
\text { Residual .. } \\
\text { Total .. }\end{array}$ & $\begin{array}{r}22 \\
5 \\
110 \\
137\end{array}$ & $\begin{array}{r}18507 \cdot 54 \\
129 \cdot 34 \\
8576 \cdot 72 \\
27213 \cdot 60\end{array}$ & $\begin{array}{r}841 \cdot 25 \\
25 \cdot 87 \\
77 \cdot 97 \\
198 \cdot 64\end{array}$ & $\begin{array}{l}\mathrm{Z}=1 \cdot 19 \\
\begin{aligned} 0 \cdot 1 & \text { per cent. } \\
& =0 \cdot 29\end{aligned}\end{array}$ \\
\hline
\end{tabular}

\section{Blood-pressure}

The literature relating to the blood-pressure and its range of variability in healthy subjects, although considerable, does not lead to precise conclusions. Variations with age and within particular age-groups await a further investigation. American insurance companies are the largest source of information on this subject, but their records are not always comparable, owing to the use of different types of sphygmomanometer; variations in the methods used; the number of observers taking readings; and the physiological variations in the subject with differing circumstances. Age, sex, heredity, body build, and temperament are possible factors influencing blood-pressure, in addition to the diurnal variations in relation to meals, rest and exercise.

With so many variables it is hardly surprising that there is little agreement as to the normal range of the blood-pressure in health (Shock and Ogden, 1939). In addition, the records of diastolic pressure are often incomplete, owing to the technical difficulty in some cases of making this observation, and to disagreement among observers as to the importance of this reading.
There are few detailed studies of blood-pressure in infancy and childhood. Cases of hypertension in children, without other pathological manifestations to account for the raised blood-pressure are rare, but have been reported (Clark, 1940; Sobel, 1941). When this increase is first apparent, and what level should be taken to indicate hypertension, is difficult to define owing to lack of normal standards for comparison based on examination of healthy children at various ages. All workers agree that the blood-pressure tends to increase with age, but there is great disagreement as to the range for particular ages, doubtless due to variations in the methods used, the observers, the subjects, and the environmental factors influencing them. (Abt and Feingold, 1930.)

In the day nurseries it was possible to standardize technique and keep the environmental factors reasonably constant. All readings were made by one observer, and the recommendations given in the report of the Joint Committees of the Cardiac Societies of Great Britain and America (1939) were followed. The instrument used for recording the pressure was a mercurial manometer. Observations were made on the right arm, with the child sitting or lying quietly on the table, and after it had become accustomed to the observer, the assistant and its own novel position. If possible two readings were taken, one at the beginning and one at the end of the other examinations. The mean of the two readings was recorded. No attempt was made to take the blood-pressure if the child was frightened, crying or angry. No child was harbouring an obvious infection. All readings were taken in the morning, at least two hours after a meal.

It has been shown that the width of the bloodpressure cuff affects the readings; narrow cuffs giving higher values than broad cuffs. (Day, 1939; Janeway, 1909; Phipps, 1915; Hensen, 1920.) These observers agree that the size of the arm is of importance, but that the width of the cuff is not significant, and all recommend the use of as wide a cuff as possible. Other workers do not agree with this (Hering, 1920; Stant and Kroetz, 1925) and recommend a cuff of standard width for varying ages. The width recommended by the AngloAmerican Committee for adults was $12 \mathrm{~cm}$. This covers half the upper arm. As children's arms vary a great deal in length, according to age, it was thought desirable to have a uniform and adequate proportion of the arm covered by the cuff in all cases so that comparable readings for the different age-groups could be obtained. The width of the blood-pressure cuff was marked off in centimetres so that it could be folded to a required measurement. The cuff was bound on to the arm so that at least half of it was covered. The average width of the cuff for children under two years was $4 \mathrm{~cm}$.; from two to four years $6 \mathrm{~cm}$.; and from four to five years $8 \mathrm{~cm}$. The pressure in the cuff was raised to about $120 \mathrm{~mm}$. of mercury and allowed to fall slowly, while the observer listened with the stethoscope over the brachial artery in the antecubital fossa. The pressure at which any sounds were first heard was 
taken as the systolic reading; the point at which sounds became muffled was taken as the diastolic reading. This was difficult to detect in small babies, and if not observed after the second attempt no further efforts were made to ascertain this latter pressure.

Table 3 shows the mean values and the percentage variation in the systolic and diastolic blood-pressures according to the age and sex of the children. Infants under six months are not included in the tables owing to the technical difficulty involved in taking an accurate reading with a mercurial manometer at this age.

TABLE 3

\begin{tabular}{|c|c|c|c|c|c|c|}
\hline \multicolumn{4}{|c|}{ Males } & \multicolumn{3}{|c|}{ Females } \\
\hline $\begin{array}{c}\text { Age } \\
\text { yr. }\end{array}$ & Total & Mean \pm S.E. & C.V. & Total & Mean $\div$ S.E. & C.V. \\
\hline \multicolumn{7}{|c|}{ Systolic Pressure } \\
\hline $\begin{array}{l}\frac{1}{2}-1 \\
1-2 \\
2-3 \\
3-4 \\
4-5\end{array}$ & $\begin{array}{l}15 \\
26 \\
46 \\
52 \\
54\end{array}$ & $\begin{array}{l}88 \cdot 53 \pm 3.74 \\
96 \cdot 15 \pm 2.99 \\
98 \cdot 91 \pm 1.85 \\
99 \cdot 89 \pm 1.83 \\
99 \cdot 26 \pm 1.38\end{array}$ & \begin{tabular}{|l}
$16 \cdot 4$ \\
$15 \cdot 8$ \\
$12 \cdot 5$ \\
$12 \cdot 4$ \\
$10 \cdot 2$
\end{tabular} & $\begin{array}{l}10 \\
25 \\
43 \\
68 \\
52\end{array}$ & $\begin{array}{l}92 \cdot 80 \pm 2 \cdot 86 \\
95 \cdot 04 \pm 2 \cdot 37 \\
92 \cdot 14 \pm 1 \cdot 85 \\
99 \cdot 85 \pm 1 \cdot 36 \\
99 \cdot 27 \pm 1 \cdot 48\end{array}$ & \begin{tabular}{|r|}
$9 \cdot 8$ \\
$12 \cdot 5$ \\
$13 \cdot 2$ \\
$11 \cdot 2$ \\
$10 \cdot 7$
\end{tabular} \\
\hline \multicolumn{7}{|c|}{ Diastolic Pressure } \\
\hline $\begin{array}{l}\frac{1}{2}-1 \\
1-2 \\
2-3 \\
3-4 \\
4-5\end{array}$ & $\begin{array}{l}14 \\
21 \\
40 \\
50 \\
52\end{array}$ & $\begin{array}{l}59 \cdot 71 \pm 2 \cdot 86 \\
66 \cdot 10 \pm 2 \cdot 63 \\
63 \cdot 70 \pm 1 \cdot 96 \\
66 \cdot 67 \pm 1 \cdot 60 \\
65 \cdot 07 \pm 0 \cdot 69\end{array}$ & $\begin{array}{r}16 \cdot 8 \\
18 \cdot 6 \\
19 \cdot 3 \\
17 \cdot 6 \\
7 \cdot 8\end{array}$ & $\begin{array}{l}17 \\
16 \\
41 \\
67 \\
50\end{array}$ & $\begin{array}{l}62 \cdot 29 \pm 3 \cdot 52 \\
64 \cdot 63 \pm 3 \cdot 74 \\
60 \cdot 00 \pm 1 \cdot 83 \\
64 \cdot 21 \pm 1 \cdot 02 \\
66 \cdot 08 \pm 1 \cdot 36\end{array}$ & $\begin{array}{l}15 \cdot 0 \\
23 \cdot 2 \\
19 \cdot 5 \\
13 \cdot 0 \\
14 \cdot 9\end{array}$ \\
\hline
\end{tabular}

S.E. = Standard Error of Sampling.

C.V. = Coefficient of Variation.

Up to four years old in both sexes the systolic blood-pressure increases with age, with one exception. Among females aged two to three the value decreases. There is little or no correlation with age in the trend of the diastolic pressure for either sex. At two to three years the value both for males and females shows a decrease.

The actual fluctuation in the systolic bloodpressure is greater than that in the diastolic, but when this variation is expressed as a percentage of the mean value by the coefficient of variation, the systolic varies less than the diastolic pressure. The respective coefficients are of the order of 12 per cent. and 15 per cent.

There is little evidence to indicate any difference in the blood-pressure between the sexes, except at two to three years old. At this period the systolic value for males exceeds that for females to a significant degree as the difference is more than twice its standard error, being $6 \cdot 77 \pm 2 \cdot 60$. The diastolic value for males at this age is also greater than that for females, but the difference lies within the limits of random fluctuation.

In the present series of cases both sexes show a positive, significant correlation between the systolic and diastolic readings, greater at some ages than at others, as shown in table 4.
TABLE 4

CORRELATION COEFFICIENTS BETWEEN SYSTOLIC AND DIASTOLIC BLOOD-PRESSURE

\begin{tabular}{c|c|c|c|c}
\hline \multicolumn{3}{c|}{ Males } & \multicolumn{2}{c}{ Females } \\
Age (yr.) & Total & Coefficient & Total & Coefficient \\
\hline $1-2$ & 21 & $0 \cdot 798 \pm 0 \cdot 224$ & 16 & $0 \cdot 719 \pm 0 \cdot 258$ \\
$2-3$ & 40 & $0 \cdot 502 \pm 0 \cdot 160$ & 41 & $0 \cdot 676 \pm 0 \cdot 158$ \\
$3-4$ & 50 & $0 \cdot 800 \pm 0 \cdot 143$ & 67 & $0 \cdot 674 \pm 0 \cdot 123$ \\
$4-5$ & 54 & $0 \cdot 572 \pm 0 \cdot 137$ & 50 & $0 \cdot 400 \pm 0 \cdot 143$ \\
& & & & \\
\hline
\end{tabular}

In the three to four age-group the coefficient for males was $0.80 \pm 0.143$ and for females $0.674 \pm$ $0 \cdot 123$. In view of this high association it was of interest to ascertain the degree of accuracy with which the diastolic blood-pressure of male children of three to four years could be predicted from a knowledge of the systolic recordings. The regression coefficient of the diastolic on the systolic bloodpressure was $+0 \cdot 729$, which implies that for a unit increase in the systolic value there is, on the average, an increase of +0.729 in the diastolic pressure. The equation connecting the two variables was: Diastolic blood-pressure $=0.729$ systolic bloodpressure -5.08 . The actual variation in the diastolic blood-pressure, as represented by its standard deviation $\sigma$, is $11 \cdot 5$. The standard deviation from the regression line is 6.9 which represents a reduction of 40 per cent. on that found from the mean alone. The equation thus allows a fairly satisfactory estimate to be made of the diastolic, from a knowledge of the systolic pressure.

In adults there is a correlation between hypertension and overweight. Whether or not there is any correlation between weight and blood-pressure within their natural variations is less certain. The necessary correlation coefficients between bloodpressure and weight were calculated, and it was found that for every age-group in this series there was a small, positive correlation, which did not exceed its standard error. Hence in children under five years old, there is no significant correlation of the blood-pressure with the weight

The observations in the present series were made when the child was awake in the case of the bloodpressure readings, and when the child was asleep in the case of the pulse-rate. The records are therefore unsuitable for showing any correlation between the two.

The evidence, both from the pulse-rates and the blood-pressure readings, suggests that two to three years old may be an age period when a significant change occurs in the circulatory system of both sexes.

\section{Conclusions}

Pulse-rates in infancy and childhood decrease with age in both sexes; in females there is a regular decrease; in males there is a more abrupt fall at two to three years old. 
There is greater variation between the sleeping pulse-rates of children in the same age-group than there is in the daily sleeping pulse-rate of the individual child.

The systolic blood-pressure in children of both sexes, with one exception among the females, increases with age up to four years old. At four to five years it declines.

At two to three years the systolic pressures in females, and the diastolic in both sexes, decrease. At this age period males have a significantly higher systolic pressure than the females.

There is a high correlation between the systolic and diastolic pressures. There is no significant correlation between the blood-pressure and bodyweight in childhood.

The evidence suggests that there may be a physiological change in the circulatory system of both sexes at two to three years old.

Thanks are due to Dr. G. C. Williams, M.O.H., Oxford City, for the facilities which made this enquiry possible; to Dr. N. Archer, Assistant M.O.H., for permission to make these observations in the day nurseries under her charge; and to the Day Nursery Staffs for their willing co-operation. Thanks are also due to Dr. W. T. Russell for statistical assistance; and to Professor J. A. Ryle for advice and criticism.

\section{REFERENCES}

Abt, A., and Feingold, B. (1930). Amer. J. Dis. Child., 40, 1285 .

Benedict, F., and Talbot, F. (1914). The gaseous metabolism of infants. Wash. D.C. (Carnegie Inst.).

Clark, H. (1940). Amer. J. Dis. Child., 59, 353.

Day, R. (1939). J. Pediat., 14, 148.

Halverson, H. (1941). J. Genet. Psych., 59, 259.

Hensen, H. (1920). Dtsch. Arch. Klin. Med., 67, 436.

Hering, E. (1920). I Ibid., 133, 306.

Janeway, T. (1909). Arch. intern. Med., 3, 474.

Joint Comm. Cardiac Soc. of Great Britain and America. (1939). Brit. med. J., 2, 184.

Phipps, G. (1915). Boston med. surg. J., 173, 476.

Schlesinger, B. (1932). Quart. J. Med., 25, 67.

Shock, N., and Ogden, E. (1939). Quart.J. exp. Physiol., $29,49$.

Sobel, I. (1941). Amer. J. Dis. Child., 61, 280.

Stant, H., and Kroetz, C. (1925). Dtsch. Arch. Klin. Med., 149, 230.

Sutherland, G., and McMichael, J. (1928), Quart. J. Med., 22, 519 . 